ISSN 1991-8631

Original Paper

http://indexmedicus.afro.who.int

\title{
Organochlorine pesticide residues in soil from sugarcane plantations in Kilimanjaro, Tanzania
}

\author{
Harieth HELLAR-KIHAMPA \\ Institute for Continuing Education, The Open University of Tanzania, P. O. Box 23409, \\ Dar es Salaam, Tanzania. \\ E-mail: hhellar@yahoo.co.uk
}

\begin{abstract}
Soil samples from the Tanganyika Planting Company (TPC) sugarcane plantations in Kilimanjaro, Tanzania, an area of intensive pesticide application, were analysed for historic and current-use pesticide contamination. Twenty eight samples were collected from 7 stations within and outside the plantations during the dry and the rainy seasons. Solid-liquid extraction and gel-permeation chromatography methods were used before analysis of pesticides by GC-ECD and GC-MS. Blank and spiked recovery tests were used to validate the analytical procedure. DDT and its metabolites ( $p, p^{\prime}$-DDD and $p, p^{\prime}$-DDE), aldrin, dieldrin, heptachlor, heptachlor epoxide, HCHs $(-\alpha,-\beta,-\delta$ and $-\gamma$ isomers), and chlordane were detected in more than $90 \%$ of the samples analysed in concentrations ranging from below detection limits (bdl) to $745.9 \mathrm{ng} / \mathrm{g} \mathrm{dw}$. The detection and concentration trends were $\sum \mathrm{DDT}>\sum \mathrm{HCH}>\sum$ heptachlor $>$ dieldrin $>\gamma$-chlordane $>$ aldrin. The highest concentration values were obtained during the dry season and in the application areas. The presence of organochlorine pesticide residues at concentrations reported in this study two decades after cessation of their use emphasizes the need for continuous monitoring and risk assessments.
\end{abstract}

(c) 2011 International Formulae Group. All rights reserved.

Keywords: Organochlorine pesticides, soil, sugarcane plantations, environmental contamination.

\section{INTRODUCTION}

Organochlorine pesticide residues are regarded as an important class of contaminants, owing to their toxicity, persistence and bioaccumulation (Den Hond et al., 2003). Although the application of these chemicals was banned or restricted in many countries more than two decades ago, their residues and degradation products are still being detected in water, air, soil, sediments and biota at significant levels, not only in the previous application sites, but also in some remote, non-application areas (Guzzella et al.,
2005; Concha-Graňa et al., 2006; Zhou et al., 2006; Sarkar et al., 2008).

Soil is the primary reservoir of pesticides. This may be through direct application of the chemicals to the soil surface, incorporation in a few inches of the soil surface or off-target drifting during application to crops. Once in the soil, pesticides may undergo a series of transformation and distribution processes. These transformation processes may have a biotic or abiotic origin and cause the degradation of pesticides through several mechanisms such as oxidation, reduction, or 
hydrolysis (Berkowitz et al., 2008). The distribution of pesticides can originate from various pathways, including volatilization, leaching, runoff, and absorption by plants. In these processes, the physico-chemical properties of pesticides and the adsorptiondesorption equilibrium in soil are the main factors involved (Sánchez-Brunete et al., 2008; Schrecket et al., 2008). Other factors such as land-use practices, type of the soil and the climatic condition of the area determine the fate of pesticides and their degradation products in the soil (Walker et al., 1999). Prolonged pesticide applications in an area may therefore lead to pesticide residues accumulation in soil and other components of the environment (Carabias-Martinez et al., 2003). The major concerns regarding pesticides in soil include the possible carryover of the pesticides and their biologically active degradation products to crops grown in later seasons, biological effects on organisms in terrestrial and aquatic ecosystems, including bioaccumulation and transfer through food chains, surface and groundwater contamination, and effects to soil fertility (Kishimba and Mihale, 2004; Hildebrandt et al., 2008;).

The Tanganyika Planting Company (TPC) sugarcane estate in Kilimanjaro region, northern of Tanzania is one of the oldest large scale pesticide users in the country. TPC was established in 1930 initially as a sisal estate, which was converted into sugar estate in 1932. Pesticides have been intensively applied in the estates since early 1940s, following devastating insect pest outbreaks that caused serious yield losses. Analysis of the yield data from TPC indicated losses of up to $25 \%$ during periods of intense pest infestations (TPC, 2002). More than twenty types of pesticides, including organochlorines, organophosphorus, carbamates and pyrethrine insecticides; and different types of herbicides such as oxadiazon were used in the sugarcane fields for more than five decades. The types and amounts of pesticides used kept on increasing over the years. Some of them, like Ethylene Dibromibe (EDB), become non- effective due to development of pest resistance and others like DDT and other organochlorines were banned from use due to environmental concerns.

Despite its over fifty-year history of intensive pesticide application, no study has assessed the soil quality of TPC sugarcane plantations and its environs. This work investigated the status of pesticide contamination in the area by establishing the levels of pesticide residues, their mobility trends, spatial and seasonal distribution trends, and effects of various physicochemical parameters in soil samples. The findings obtained may be useful as baseline information for future monitoring programs.

\section{MATERIALS AND METHODS \\ Sampling site}

The TPC estate is located at about 50

Km South of Mount Kilimanjaro, at Arusha Chini wetlands and Kahe plains. The sugarcane plantation covers an area of about 14,000 ha of cultivated land surrounded by nine villages, namely Chekereni, Kiyungi, Kikavu, Newland, Mtakuja, Msitu wa Tembo, Mserekia, Samanga and Mikocheni, with a shortest distance of about $1 \mathrm{~km}$ from the sugarcane farms. Also, there are five camps where workers and their families live. Information about types, duration of use and pesticide application methods at the estate was gathered during field survey.

Seven sampling sites (Figure 1) were selected from which 28 samples (each $100 \mathrm{~g}$ ) were collected in two sampling campaigns. Sampling sites were selected from the application areas (sugarcane plots) and some locations of increasing distances from the application areas. Sample collection was done using standard methods (Åkerblom, 1995). Samples were packed in cold boxes and transported to the Department of Chemistry, University of Dar es Salaam where they were kept frozen at $4{ }^{\circ} \mathrm{C}$ prior to extraction.

\section{Sample preparation and extraction}

Water content in the soil samples was determined by heating $20 \mathrm{~g}$ of the samples at 
$105^{\circ} \mathrm{C}$ for $12 \mathrm{~h}$. The samples were then cooled to room temperature and re-weighed to evaluate the loss-on-ignition. The percentage weight losses were equated to the water content in the soil samples. Samples for pesticide residues analysis were homogenized, screened and extracted by the solid-liquid extraction method as described by Åkerblom (1995). Sub-samples of $20 \mathrm{~g}$ were put in stoppered flasks, added with $14 \mathrm{ml}$ of $0.2 \mathrm{M}$ ammonium chloride, swirled and left for 15 min to open up the soil structure. $100 \mathrm{ml}$ cyclohexane/acetone $(1: 1 \mathrm{v} / \mathrm{v})$ solutions were then added to the mixture, shaken vigorously for $1 \mathrm{~min}$ and then less vigorously about every $10 \mathrm{~min}$ for at least one hour and passed through ultrasonic bath for $5 \mathrm{~min}$. Water was then added cautiously to fill the stoppered flask. The organic phases were transferred using a pipette to E-flasks containing $20 \mathrm{~g}$ sodium sulphate, and then decanted through glass wool into evaporation flasks. The sodium sulphate was then rinsed with $30 \mathrm{ml}$ acetone and decanted through the same glass wool plug. The aqueous phases were then discarded. The sample extracts were concentrated in a BÜCHI vacuum rotary evaporator at $30{ }^{\circ} \mathrm{C}$, and the solvent changed to cyclohexane/ethyl acetate $(1: 1 \mathrm{v} / \mathrm{v})$ for clean-up by gel permeation chromatography (GPC), using the method described by Åkerblom (1995). Cleaned sample extracts were concentrated to $2 \mathrm{ml}$ in cyclohexane/ acetone $(9: 1 \mathrm{v} / \mathrm{v})$ and kept in teflon-stoppered glass sample vials ready for GC analysis.

\section{Sample analysis}

The sample extracts were analyzed by a Varian Star 3400 gas chromatography equipped with ${ }^{63} \mathrm{Ni}$ electron capture detector (ECD) at the Department of Chemistry, University of Dar es Salaam, Tanzania. Nonpolar (SE-30) and semi-polar (OV-1701) capillary columns of dimensions $30 \mathrm{~m}$ x 0.32 $\mathrm{mm} \times 0.25 \mu \mathrm{m}$ liquid thickness were used. Nitrogen was used as both a carrier and make up gas, flowing at the rate of $30 \pm 1 \mathrm{ml} / \mathrm{min}$. The injector and detector temperatures were set at $250{ }^{\circ} \mathrm{C}$ and $300{ }^{\circ} \mathrm{C}$ respectively. The column temperature was initially set at $90{ }^{\circ} \mathrm{C}$, held for $1 \mathrm{~min}$ and then raised to $180{ }^{\circ} \mathrm{C}$ at the rate of $30{ }^{\circ} \mathrm{C} / \mathrm{min}$. It was further raised to 260 ${ }^{\circ} \mathrm{C}$ at the rate of $4{ }^{\circ} \mathrm{C} / \mathrm{min}$ and maintained at this temperature for $12 \mathrm{~min}$.

Pesticide residues were identified and quantified by using external reference standards. Retention times and peak heights of the detected residues were compared to those of the reference pesticides. Parathion was used as an internal reference standard for the determination of compounds' relative retention times. Identified peaks were confirmed by analyzing the same sample extracts by a Hewlett Packard model 5890 GC-MS with CP-Sil $19 \mathrm{CB}$ and CP-Sil $5 \mathrm{CB}$ columns, $20 \mathrm{~m}$ x $0.32 \mathrm{~mm}$ i.d. x0.25 $\mu \mathrm{m}$ liquid thickness (Chrompack Sverige AB, Nacka Sweden), at the Department of Environmental Assessment, SUAS, Sweden). Helium was used as a carrier gas at $1.9 \mathrm{ml} / \mathrm{min}$. Hydrogen and air were flowing at 120 and $100 \mathrm{ml} / \mathrm{min}$ respectively. The injector and detector temperatures were set at $270{ }^{\circ} \mathrm{C}$ and $300{ }^{\circ} \mathrm{C}$ respectively. The column temperature was initially set at $70{ }^{\circ} \mathrm{C}$, held for $1 \mathrm{~min}$ and then raised to $230{ }^{\circ} \mathrm{C}$ at the rate of $30{ }^{\circ} \mathrm{C} / \mathrm{min}$. It was further raised to $280{ }^{\circ} \mathrm{C}$ at the rate of 4 ${ }^{\circ} \mathrm{C} / \mathrm{min}$ and maintained at this temperature for $10 \mathrm{~min}$.

\section{Quality control and quality assurance}

All reagents used were of analytical grade, and the solvents were of chromatographic grade. Pesticide standards solutions (99\% certified purity) were ordered from Dr. Ehrenstorfer (Augsburg, Germany). Sodium chloride and anhydrous sodium sulphate were heated at about $400{ }^{\circ} \mathrm{C}$ for two hours and allowed to cool to constant temperature in desiccators to remove interfering substances before use. Glassware used had Teflon caps and were cleaned with detergents and distilled water, thoroughly rinsed with acetone and dried overnight in an oven before use.

The method detection limits (MDLs) of the organochlorines were determined as the concentrations of analytes in a sample that 
gave rise to a peak with a signal-to-noise ratio $(\mathrm{S} / \mathrm{N})$ of 3. Soil spiked with target compounds were used for evaluation of the detection limits. Blank tests and recovery tests were conducted to check for interference and crosscontamination (Hill, 2000). For every batch of 7 samples analysed, 1 laboratory-grade sand was analysed as a blank sample, and 1 laboratory-grade sand spiked sample were simultaneously analysed. The method validation was done by spiking laboratorygrade sand with mixtures of organochlorine pesticide standard solutions of known concentrations (50-300 $\mathrm{ng} / \mathrm{l})$, that were extracted, cleaned-up and analysed as the ordinary samples. The percentage recoveries were calculated as the ratio of the actual concentrations obtained after GC analysis to the added (spiked) concentrations.

\section{Statistical analysis}

Mean concentrations of pesticide residues in soil were calculated using a statistical package INSTANT ${ }^{\circledR}$. Multiple comparison with one way ANOVA were used to test the significant differences of pesticide concentrations among the sampling sites and across the two seasons $(\alpha=0.05)$.

\section{RESULTS}

Water content, spiked recoveries and blank tests

Water contents in the soil samples from each sampling site for the two seasons are summarized in Figure 2. The water contents were higher during the rainy season (11.8 $23.2 \%)$ than during the dry season (4.0 $12.9 \%$ ). This was expected since during rainfalls the soil is wetter than during the dry season. The mean percentage recoveries and detection limits of the quantified organochlorines are summarized in Table 2. The mean recoveries $(68.8 \pm 1.3$ to $88.7 \pm$ $0.9 \%$ ) were within the acceptable range of 70 - 120\% (Åkerblom, 1995); and the blank reference samples had no traces of the targeted analytes. These data confirmed the practicability of the analytical protocols herein employed in the determination of organochlorine pesticide residues in the soil samples.

\section{Concentrations of organochlorine pesticide residues in the soil samples}

The results of the analysis showed the presence of 12 organochlorine pesticide residues and metabolites in the soil samples. The concentration ranges and means of the compounds detected are summarized in Table 3. The mean concentrations ranged from $0.7 \pm$ 1.3 ( $\gamma$-Chlordane) to $170.4 \pm 266.8 \mathrm{ng} / \mathrm{g} \mathrm{dw}$ (p,p'-DDT).

\section{Spatial and seasonal variations of organochlorine pesticide residues in soil \\ The distribution of various} organochlorine pesticide residues in the soil samples from the 7 sampling stations showed a wide range of variation as summarized in Table 4. The concentration trend was $\sum \mathrm{DDT}>\sum \mathrm{HCH}>\sum$ heptachlor $>$ dieldrin $>$

$\gamma$ chlordane $>$ aldrin. The detection frequencies of DDTs and HCHs were $100 \%$ of the samples analysed, indicating a wide occurrence of the compounds. Aldrin, dieldrin and chlordane were detected in samples from the sugarcane fields only (S1, S2 and S3). Total organochlorine pesticide levels varied from 25.9 to $1547.8 \mathrm{ng} / \mathrm{g} \mathrm{dw}$, with the highest concentrations detected at site S3 and the lowest at S7.

Figure 4 compares the total concentrations of the pesticide residues quantified during the dry season with those of the rainy season. It was observed that in each of the site, concentrations and detection frequencies were higher during the dry season than during the rainy season. This might be attributed to the fact that during the dry season the water content in the soil is low and therefore allows more pesticides to reach bare soil, whereas during rainfall pesticides are washed out from the soil surface and taken away by the water flow. 


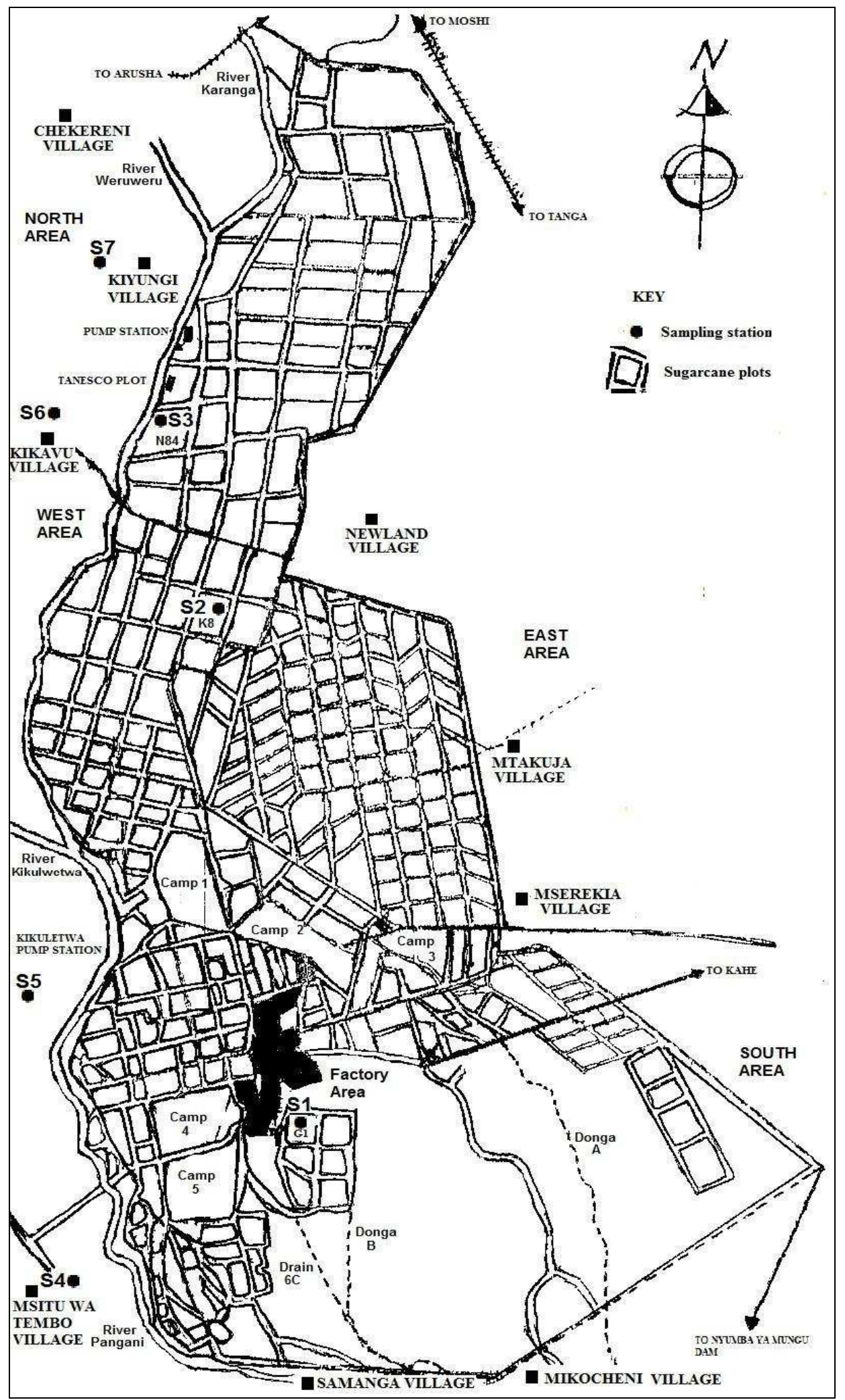

Figure 1: Map of TPC sugarcane plantations showing the sampling stations. 


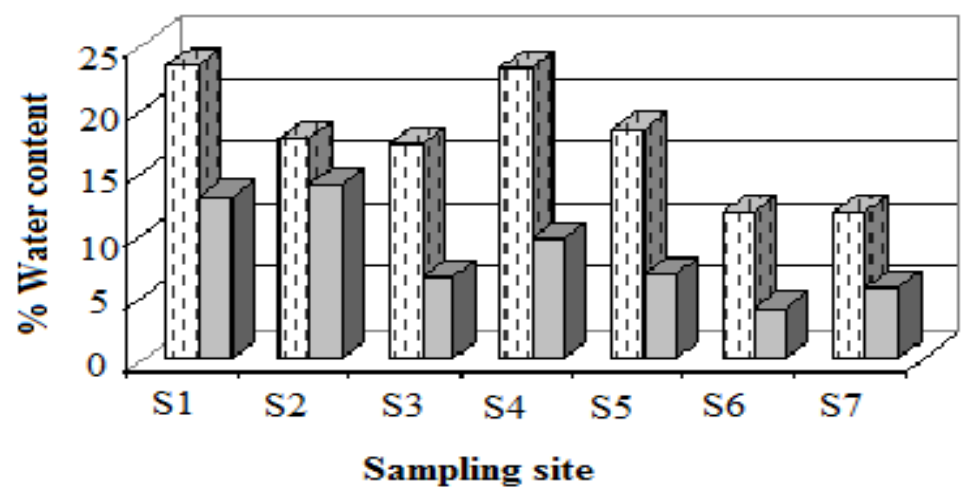

\begin{tabular}{|l|l|}
\hline Rainy season \\
\hline
\end{tabular}

Figure 2: Percentage water contents in soil samples.

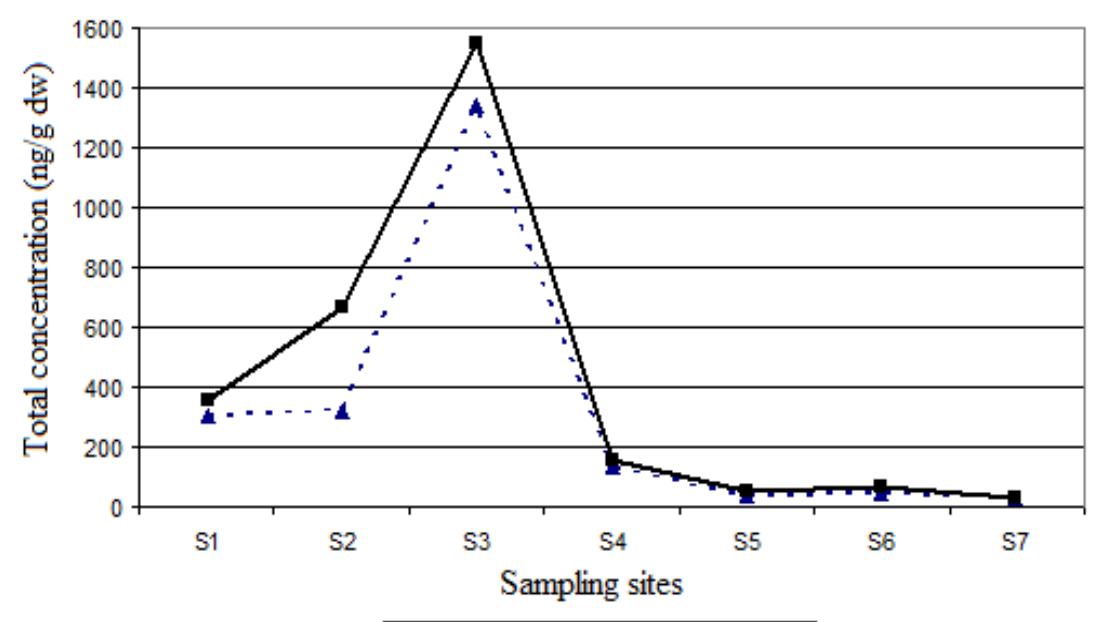

- - Rainy Season $\rightarrow$-Dry Season

Figure 4: Seasonal variations in pesticide residues' concentrations.

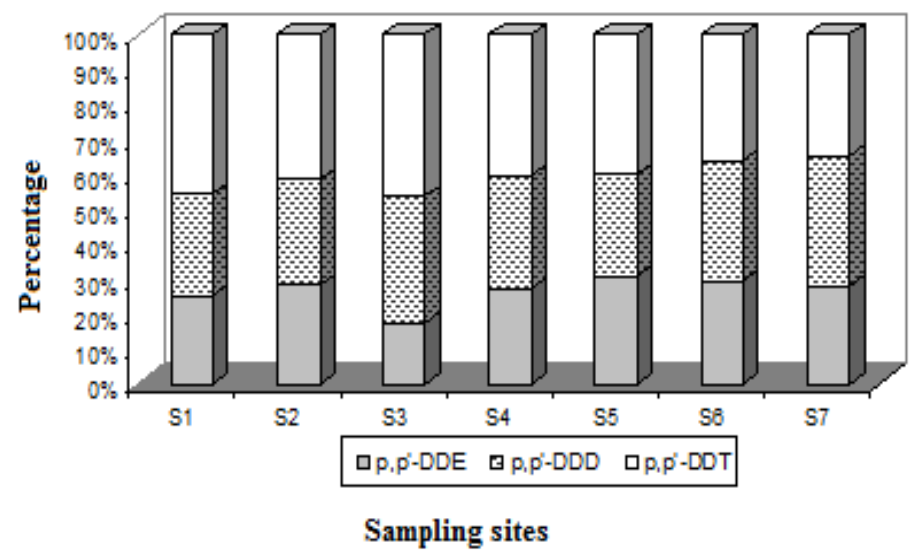

Figure 3: Contribution of individual metabolites to the total DDT concentrations in TPC soil Samples. 
Table 1: Sampling sites.

\begin{tabular}{cccc}
\hline No. & Code & Site name & Site description \\
\hline 1. & S1 & G1 & Sugarcane plot \\
2. & S2 & K8 & Sugarcane plot \\
3. & S3 & N84 & Sugarcane plot \\
4. & S4 & Msitu wa Tembo & Non-target area \\
5. & S5 & Kikuletwa & Non-target area \\
6. & S6 & Kikavu & Non-target area \\
7. & S7 & Kiyungi & Non-target area \\
\hline
\end{tabular}

Table 2: Mean percentage recoveries and detection limits of the analyzed organochlorines obtained from the 4 recovery tests.

\begin{tabular}{lcc}
\hline Pesticide & $\begin{array}{c}\text { \% Mean recovery } \pm \text { SD } \\
(\mathbf{n}=\mathbf{4} \text {; CL 95\% })\end{array}$ & $\begin{array}{c}\text { Detection limits } \\
(\mathbf{n g} / \mathbf{g ~ d w})\end{array}$ \\
\hline$\alpha-\mathrm{HCH}$ & $71.5 \pm 0.9$ & 0.1 \\
$\beta-\mathrm{HCH}$ & $76.0 \pm 0.8$ & 0.3 \\
$\gamma-\mathrm{HCH}$ & $81.7 \pm 1.7$ & 0.1 \\
$\delta$-HCH & $74.0 \pm 2.4$ & 0.2 \\
Aldrin & $75.2 \pm 2.5$ & 0.2 \\
Heptachlor & $75.7 \pm 1.2$ & 0.4 \\
Heptachlor epoxide & $68.8 \pm 1.3$ & 0.5 \\
$\gamma$-Chlordane & $74.5 \pm 0.6$ & 0.2 \\
Dieldrin & $76.2 \pm 2.6$ & 0.2 \\
$p, p$-DDE & $78.3 \pm 0.9$ & 0.3 \\
$p, p$ '-DDD & $77.2 \pm 1.7$ & 0.4 \\
$p, p$-DDT & $88.7 \pm 0.9$ & 0.5 \\
\hline
\end{tabular}

Table 3: Pesticide residues detected in soil samples from TPC plantations and environs $(\mathrm{n}=7, \mathrm{CL}=$ $95 \%)$.

\begin{tabular}{lcccc}
\hline \multirow{2}{*}{ Pesticide } & \multicolumn{2}{c}{ Rainy season $(\mathbf{n g} / \mathbf{g}$ dw) } & \multicolumn{2}{c}{ Dry season $(\mathbf{n g} / \mathbf{g ~ d . w})$} \\
\cline { 2 - 5 } & Range & Mean \pm SD & Range & Mean \pm SD \\
\hline$\alpha$-HCH & $<0.1-37.3$ & $11.5 \pm 12.8$ & $<0.1-43.9$ & $12.7 \pm 15.1$ \\
$\beta$-HCH & $2.5-51.4$ & $16.5 \pm 17.2$ & $1.3-62.7$ & $17.7 \pm 20.9$ \\
$\gamma$-HCH & $<0.1-23.9$ & $9.4 \pm 9.1$ & $<0.1-25.2$ & $9.6 \pm 8.2$ \\
$\delta$-HCH & $<0.2-3.5$ & $1.2 \pm 1.4$ & $<0.2-4.8$ & $1.9 \pm 2.2$ \\
Aldrin & $<0.2-2.0$ & $0.6 \pm 0.8$ & $<0.2-3.4$ & $0.8 \pm 0.8$ \\
Heptachlor & $<0.4-5.2$ & $1.8 \pm 1.9$ & $<0.4-8.4$ & $2.4 \pm 4.8$ \\
Heptachlor epoxide & $<0.5-13.5$ & $2.6 \pm 4.8$ & $<0.5-23.2$ & $3.9 \pm 8.5$ \\
$\gamma$-Chlordane & $<0.2-3.6$ & $0.7 \pm 1.3$ & $<0.2-5.9$ & $1.4 \pm 2.1$ \\
Dieldrin & $<0.2-13.9$ & $3.6 \pm 5.9$ & $<0.2-16.8$ & $4.7 \pm 7.7$ \\
$p, p$ '-DDE & $8.4-217.2$ & $55.8 \pm 74.6$ & $6.5-220.4$ & $77.0 \pm 90.9$ \\
$p, p$ '-DDD & $9.0-456.7$ & $93.0 \pm 162.1$ & $4.9-486.3$ & $108.9 \pm 172.9$ \\
$p, p$ '-DDT & $24.6-578.4$ & $120.6 \pm 205.2$ & $11.2-745.9$ & $170.4 \pm 266.8$ \\
\hline
\end{tabular}


H. HELLAR-KIHAMPA. / Int. J. Biol. Chem. Sci. 5(1): 247-257, 2011

Table 4: Distribution of organochlorine pesticide residues in soil from TPC ( $\mathrm{n}=7, \mathrm{CL}=95 \%$ ).

\begin{tabular}{|c|c|c|c|c|c|c|c|c|}
\hline \multirow[b]{2}{*}{ Site } & \multicolumn{8}{|c|}{ Rainy season (Conc. ng/g dw) } \\
\hline & ${ }^{*} \sum \mathrm{HCH}$ & ${ }^{*} \sum$ DDT & ${ }^{*} \sum$ Heptac. & Aldrin & Dieldrin & Chlord. & $\begin{array}{l}\text { Total } \\
\text { OCPs }\end{array}$ & $\frac{D D E+D D D}{\sum D D T}$ \\
\hline S1 & $110.7 \pm 1.3$ & $194.1 \pm 0.8$ & $2.7 \pm 0.5^{\mathrm{A}}$ & bdl & bdl & bdl & $307.5 \pm 2.6$ & 0.54 \\
\hline $\mathrm{S} 2$ & $64.3 \pm 1.0$ & $237.3 \pm 1.6$ & $5.8 \pm 0.4$ & $2.0 \pm 1.3^{\mathrm{A}}$ & $10.5 \pm 1.3$ & bdl & $319.9 \pm 5.6$ & 0.58 \\
\hline S3 & $47.9 \pm 0.7$ & $1252.2 \pm 1.0$ & $18.7 \pm 1.0$ & $1.5 \pm 0.2^{\mathrm{A}}$ & $13.9 \pm 1.3^{\mathrm{A}}$ & $3.6 \pm 0.4$ & $1337.8 \pm 4.6$ & 0.54 \\
\hline S4 & $26.5 \pm 0.5$ & $106.1 \pm 1.1$ & bdl & bdl & bdl & bdl & $132.6 \pm 1.6$ & 0.59 \\
\hline S5 & $11.6 \pm 0.5$ & $27.2 \pm 1.2$ & bdl & bdl & bdl & bdl & $38.8 \pm 1.7$ & 0.59 \\
\hline S6 & $8.6 \pm 0.6$ & $37.5 \pm 0.7$ & bdl & bdl & bdl & bdl & $46.1 \pm 1.3$ & 0.64 \\
\hline S7 & $2.5 \pm 0.2^{\mathrm{A}}$ & $33.1 \pm 1.3$ & bdl & bdl & bdl & bdl & $35.6 \pm 1.5$ & 0.65 \\
\hline \multicolumn{9}{|c|}{ Dry season (Conc. ng/g dw) } \\
\hline $\mathrm{S} 1$ & $136.6 \pm 1.1$ & $214.9 \pm 1.9$ & $2.5 \pm 1.0^{\mathrm{A}}$ & bdl & bdl & $1.3 \pm 0.8^{\mathrm{A}}$ & $355.3 \pm 4.8$ & 0.53 \\
\hline S2 & $62.1 \pm 1.0$ & $583.5 \pm 3.4$ & $2.0 \pm 0.3$ & $2.1 \pm 1.1^{\mathrm{A}}$ & $16.8 \pm 1.0^{\mathrm{B}}$ & $1.9 \pm 0.7^{\mathrm{A}}$ & $668.4 \pm 7.5$ & 0.58 \\
\hline S3 & $35.9 \pm 0.5$ & $1452.6 \pm 2.1$ & $36.4 \pm 0.8$ & $1.8 \pm 0.7^{\mathrm{A}}$ & $15.2 \pm 0.9^{\mathrm{A}, \mathrm{B}}$ & $5.9 \pm 0.5$ & $1547.8 \pm 5.5$ & 0.40 \\
\hline S4 & $24.1 \pm 0.8$ & $129.6 \pm 1.0$ & bdl & bdl & bdl & bdl & $153.7 \pm 1.8$ & 0.61 \\
\hline S5 & $17.3 \pm 0.5$ & $41.0 \pm 0.8$ & bdl & bdl & bdl & bdl & $58.3 \pm 1.3$ & 0.55 \\
\hline S6 & $14.2 \pm 0.3$ & $52.7 \pm 1.2$ & bdl & bdl & bdl & bdl & $66.9 \pm 0.8$ & 0.59 \\
\hline S7 & $2.3 \pm 0.4^{\mathrm{A}}$ & $22.6 \pm 1.1$ & bdl & bdl & bdl & bdl & $25.9 \pm 1.5$ & 0.50 \\
\hline
\end{tabular}

$\mathrm{bdl}=$ below detection limit; ${ }^{*}$ For summation bdl was assigned a value of zero; $\sum \mathrm{HCH}=\alpha-\mathrm{HCH}+\beta-\mathrm{HCH}+\gamma-\mathrm{HCH}+\delta-\mathrm{HCH}$;

$\sum \mathrm{DDT}=p, p^{\prime}-\mathrm{DDT}+p, p^{\prime}-\mathrm{DDE}+p, p^{\prime}-\mathrm{DDT} ; \sum$ Heptac. $=$ heptachlor + heptachlor epoxide; Chlord $=\gamma$-Chlordane 


\section{DISCUSSION}

The detection of organochlorine pesticide residues in soil at this area is associated with the past applications of the chemicals in the sugarcane plantations. From Table 3, it can be observed that the concentrations of DDTs were much higher than the rest of the organochlorines. The ability of pesticide residues to bind to soil particles depends on their lipophilicity, which is estimated by their octanol-water partition coefficient $\left(\mathrm{K}_{\mathrm{ow}}\right)$ (Scheunert, 1992). The high concentrations of DDT and its metabolites may be due to the fact that they have the longest half-life and the greatest partition coefficient, thus they are the most persistent (Hites and Day, 1992). Furthermore, their extremely low solubility in water and heavy applications causes them to be retained and accumulated to a greater degree in the top soil layers (Tao et al., 2005).

Few studies on soil contamination with pesticide residues in agricultural areas are available in Tanzania. One such study was conducted in Lake Victoria basin, an intense cotton growing area with a long-term history of organochlorine pesticides application. The study revealed the presence of $p, p^{\prime}$-DDT and its metabolite $p, p^{\prime}$-DDE in concentrations ranging between $2-12 \mathrm{ng} / \mathrm{g}$ in soil samples, which were lower than in the present study. The different pesticide residues concentrations observed in the two studies might be attributed to a number of factors such as soil properties, climatic conditions and pesticide application history and methods (Henry and Kishimba, 2003). The average composition of DDT compounds in the investigated soil samples had almost similar variations in all the sampling stations, except $\mathrm{S} 3$ which had the lowest levels of $p, p$ '-DDE (Figure 3). The ratio of the degradation products to the sum DDTs that were greater than 0.5 (Table 4) indicates that the soil samples were dominated by the degradation products from past applications. DDT normally degrades under aerobic condition to DDE and under anaerobic condition to DDD (Tadeo, 2008). The ratio of $(\mathrm{DDE}+\mathrm{DDD}) / \sum \mathrm{DDT}>0.5$ indicate long- term contamination with DDTs (Dimond and Owen, 1996).

Hexachlorohexane $(\mathrm{HCH})$, commonly known as Lindane, was intensively used at TPC since 1946 before it was banned in early 1980s. Table 3 also shows that $\mathrm{HCH}$ isomers $(\alpha-\mathrm{HCH}, \beta-\mathrm{HCH}, \gamma-\mathrm{HCH}$ and $\delta-\mathrm{HCH})$ were detected in the soil samples in concentrations ranging from 1.3 to $62.7 \mathrm{ng} / \mathrm{g} \mathrm{dw}$ with a general trend of $\beta-\mathrm{HCH}>\alpha-\mathrm{HCH}>\gamma-\mathrm{HCH}>\delta$ $\mathrm{HCH}$. The $\beta$ - isomer was the most abundant isomer, with an average $48 \%$ of the total HCHs. These findings are consistent with other studies that reported $\beta-\mathrm{HCH}$ as more resistant to hydrolysis and environmental degradation and thus the dominant isomer in soils (Zhang et al., 2002). $\delta$-HCH is the least persistent of the $\mathrm{HCH}$ isomers and seldom found in environmental samples. The low ratio of $\gamma-\mathrm{HCH}$ to $\alpha-\mathrm{HCH}$ indicates the past use of technical grade $\mathrm{HCH}$ that consists of only about $10-12 \%$ of $\gamma-\mathrm{HCH}$ and $70-80 \%$ of $\alpha-\mathrm{HCH}$ (Tomlin, 2000).

Heptachlor and heptachlor epoxide were detected in samples from the sugarcane plantations only (Table 3). Concentrations of heptachlor were lower than those of heptachlor epoxide in all of the three sites. It has been established that in the natural environment heptachlor is mostly transformed through both biotic and abiotic processes to heptachlor-epoxide. Consequently, heptachlor is rarely found in environmental samples (Pandit et al., 2001).

Aldrin and dieldrin are two closely related organochlorines due to the fact that when aldrin is applied in the field, it is rapidly broken down to dieldrin (Scheunert, 1992). The overall frequency of detection of aldrin and dieldrin in the analysed soil samples were quite low (Table 3). Both compounds were simultaneously detected in only two of the sites. Concentrations of aldrin were lower than those of dieldrin, indicating the possibility of contribution from long-term degradation of aldrin.

The levels of organochlorine pesticide residues in TPC soils occurred in the order $\mathrm{S} 2>\mathrm{S} 3>\mathrm{S} 1>\mathrm{S} 4>\mathrm{S} 6>\mathrm{S} 5>\mathrm{S} 7 \quad$ (Table 4). This 
shows that pesticide residues concentrations were significantly higher in soil samples from the application areas (S1 to S3) than from the environs ( $\mathrm{S} 4$ to $\mathrm{S} 7$ ), thus indicating the sugarcane plantations as the source of these pollutants in the area. Similar observation was reported by Henry and Kishimba (2003) in which concentrations of organochlorine pesticide residues were higher in the soil from the cotton fields than the surrounding areas.

\section{Conclusion}

Standardized methods were applied for the analysis of organochlorine pesticide residues in soil samples from a sugarcane growing area in Tanzania. Twelve organochlorine pesticide residues and metabolites were detected in the analysed samples. Samples were characterized mainly by DDTs and $\mathrm{HCHs}$ which were detected in all of the samples. Heptachlor, chlordane, aldrin and dieldrin were detected in lower concentrations in only three of the sites. Different contamination patterns were observed among sampling sites, where the concentrations of OCPs were higher in soil samples collected from the sugarcane plantation than those from the surrounding areas. The detection of lower levels of parent compounds than the degradation products observed in all sampling stations implies that the contaminants are from past usage of the chemicals. Even though the levels of pesticides residues in the soil reported in this study are generally low, the fact that these chemicals still persist in the environment after a period of nearly two decades after cessation of use emphasizes the need for continuous monitoring and risk assessment. It is therefore recommended that further research should be conducted to determine the amount of pesticide residues in water and sediments, as well as put up mechanisms for monitoring residual levels in the ecosystem and food chain.

\section{ACKNOWLEDGEMENTS}

The author would like to acknowledge Sida/SAREC through the Faculty of Science,
University of Dar es Salaam for financial support. Professor Michael Kishimba of the Department of Chemistry, University of Dar es Salaam and Professor M. Åkerblom of the International Science Programme (ISP), Uppsala University for material and technical assistance. Technicians at the Department of Chemistry, University of Dar es Salaam and the Department of Environmental Assessment at the Swedish University of Agricultural Sciences for assistance with GC analyses. The Management of Tanganyika Planting Company for allowing the study to be conducted in the area, and Mr. Juma Kapunda, Mr. Epaphra Mosi and Mr. Godsten Maro of TPC sugarcane plantations for assistance during the sampling campaigns.

\section{REFERENCES}

Åkerblom M. 1995. Guidelines for environmental monitoring of pesticide residues for the SADC region. SADC/ELMS, Monitoring Techniques series 3 Lesotho.

Berkowitz B, Dror I, Yaron B. 2008. Contaminant Geochemistry: Interactions and Transport in the Subsurface Environment. Sringer-Verlag: Berlin.

Carabias-Martinez R, Rodriguez-Gonzalo E, Fernandez-Laespada ME, Calvo-Seronero L, Sanchez-San Roman FJ. 2003. Evolution over time of the agricultural pollution of waters in an area of Salamanca and Zamora (Spain). Water Res., 37(4): 928-938.

Concha-Graňa E, Turnes-Carou MI, Muniategui-Lorenzo S, López-Mahía P, Prada-Rodríguez D, Fernández-Fernández E. 2006. Evaluation of $\mathrm{HCH}$ isomers and metabolites in soils, leachates, river water and sediments of a highly contaminated area. Chemosphere, 64: 588-595.

Den Hond F, Groenewegen P, van Straalen NM. 2003. Pesticides: Problems, Improvements, Alternatives. Blackwell Science Ltd, a Blackwell Publishing Company: Oxford. 
Dimond JB, Owen RB. 1996. Long-term residue of DDT compounds in forest soils. Mar. Environ. Pollution, 92: 227-230.

Guzzella L, Roscioli C, Vigano L, Saha M, Sarkar SK, Bhattacharya A. 2005. Evaluation of the concentration of $\mathrm{HCH}$, DDT, HCB, PCB and PAH in the sediments along the lower stretch of Hugli estuary, West Bengal, northeast India. Environ. Int., 31: 523-534.

Henry L, Kishimba MA. 2003. Levels and chemodynamics of pesticide residues in water, soil, and sediment from Southern Lake Victoria, Mwanza Tanzania. Tanz. J. Sci., 29: 78-79.

Hildebrandt A, Guillamón M, Lacorte S, Tauler R, Barcelo D. 2008. Impact of pesticides used in agriculture and vineyards to surface and groundwater quality (North Spain). Water Res., 42: 3315-3326.

Hill A. 2000. Quality Control Procedures for Pesticide Residues, Guidelines for Residues Monitoring in the European Union ( $2^{\text {nd }}$ edn). Document no. SANCO/ 3103/2000, European Commission.

Hites RK, Day HR. 1992. Unusual persistence of DDT in some western USA soils. Bull. Environ. Contam. Toxicol., 48: 259-264.

Kishimba MA, Mihale MJ. 2004. Levels of pesticide residues and metabolites in soil at Vikuge Farm, Kibaha District, Tanzania - A classic case of soil contamination by obsolete pesticides. Tanz. J. Sci., 30(2): 77-87.

Pandit GG, Mohan AM, Jha SK, Krishnamoorthy TM, Kale SP, Raghu K, Murthy NBK. 2001. Monitoring of organochlorine pesticide residues in the Indian marine environment. Chemosphere, 44: $301-305$.

Sánchez-Brunete C, Albero B, Tadeo JL. 2008. Determination of pesticides in soil. In Analysis of Pesticides in Food and Environmental Samples. Tadeo JL. (ed) CRC Press: Taylor \& Francis Group, LLC, Boca Raton, Fl.
Sarkar SK, Bhattacharya BD, Bhattacharya A, Chatterjee M, Alam A, Satpathy KK, Jonathan MP. 2008. Occurrence, distribution and possible sources of organochlorine pesticide residues in tropical coastal environment of India: An overview. Environ. Int., 34: 1062-1071.

Scheunert I. 1992. Physical and physicochemical processes governing the residue behaviour of pesticides in terrestrial ecosystems. In Chemistry of Plant Protection (vol. 8). Ebing W (ed). Springer-Verlag: Berlin; 1-18.

Schrecket E, Geret F, Gontier L, Treilhou M. 2008. Development and validation of a rapid multiresidue method for pesticide determination using gas chromatographymass spectrometry: A realistic case in vineyard soils. Talanta, 77: 298-303.

Tadeo JL. 2008. Analysis of Pesticides in Food and Environmental Samples. CRC Press, Taylor \& Francis Group, LLC: Boca Raton, Fl.

Tao S, Xu FL, Wang J, Liu WX, Gong ZM, Fang JY, Zhu LZ, Luo YM. 2005. Organochlorine pesticides in agriculture soil and vegetables from Tianjin, China. Environ. Sci. Technol., 39: 2494-2499.

Tomlin CD. 2000. The Pesticide Manual, (12th edn). Crop Protection Publications: London.

Walker K, Vallero DA, Lewis RG. 1999. Factors influencing the distribution of lindane and other hexachlorocyclohexanes in the environment. Environ. Sci. Technol., 33: 4373-4378.

Zhang Z, Hong H, Zhou JL, Yu G, Chen W, Wang X. 2002. Transport and fate of organochlorine pesticides in the River Wuchuan, Southeast China. J. Environ. Monitor., 4: 435-441.

Zhou R, Zhu L, Yang K, Chen Y. 2006. Distribution of organochlorine pesticides in surface water and sediments from Qiantang River, East China. J. Hazard. Mater., A137: 68-75. 